\title{
A QUINTA GERAÇÃO DE DIREITOS FUNDAMENTAIS
}

\author{
PAULO BONAVIDES
}

RESUMO: O artigo versa sobre a importância de reconhecimento jurídico do direito à paz e sua íntima integração a compreensão de democracia. Destaca a paz como um direito fundamental de quinta geração que legitima o estabelecimento da ordem, da liberdade e do bem comum na convivência dos povos. Assim, a nova dimensão de direitos fundamentais reserva ao direito à paz o papel central de supremo direito da humanidade.

PALAVRAS-CHAVE: Direito à Paz; Direitos Fundamentais; Democracia.

ABSTRACT: The article subject is the importance of legal recognition of the right to peace and its close integration understanding of democracy. Underlines, peace as a fundamental right of a fifth generation that legitimizes the establishment of the order, freedom and the common good in peaceful people coexistence. Thus for, this new dimension of fundamental rights reserves the central role of humanity's supreme law to the right to peace.

KEYWORDS: Right to Peace; Fundamental Rights; Democracy.

SUMÁRIO: 1 . O direito à paz, direito da quinta geração: sua trasladação da terceira para a quinta geração de direitos fundamentais. 2. O reconhecimento da paz como direito na doutrina e na jurisprudência. 3. A visualização da paz enquanto direito da quinta geração. 4. A pré-compreensão da paz: a era da legitimidade. 5. O flagelo das ditaduras constitucionais. 6. Vicissitudes da evolução constitucional do Brasil ao tempo do Império. 7. Em países periféricos não vinga Estado de Direito sem Estado Social; a necessidade precípua de preservar a soberania e fazer da paz um direito. 8 . O direito à paz um direito fundamental de nova dimensão.

SUMMARY: 1 . The right to peace, right of the fifth generation: its transfer from the third to the fifth generation of fundamental rights. 2. The recognition of peace and law in doctrine and jurisprudence. 3 . The view of peace as a right of the fifth generation. 4 . The pre-understanding of peace: the era of legitimacy. 5. The scourge of constitutional dictatorship. 6. Transformations of constitutional evolution in Brazil at the time of the Empire. 7. In peripheral countries does not prevail rule of law without the welfare state; the main need to preserve the sovereignty and make peace a right. 8 . The right to peace a fundamental right of a new dimension.

\section{O DIREITO À PAZ, DIREITO DA QUINTA GERAÇÃO: SUA TRASLADAÇÃO DA TERCEIRA PARA A QUINTA GERAÇÃO DE DIREITOS FUNDAMENTAIS}

A concepção da paz no âmbito da normatividade jurídica configura um dos mais notáveis progressos já alcançados pela teoria dos direitos fundamentais.

* Catedrático Emérito da Universidade Federal do Ceará, Doutor Honoris Causa pela Universidade de Lisboa e agraciado com a Medalha Rui Barbosa da Ordem dos Advogados do Brasil. Fundador e Presidente do Conselho Diretivo da Revista Latino-Americana de Estudos Constitucionais. 
Karel Vasak, o admirável precursor, ao colocá-la no rol dos direitos da fraternidade, a saber, da terceira geração, o fez, contudo, de modo incompleto, teoricamente lacunoso.

Não desenvolveu as razões que a elevam à categoria de norma. Sobretudo aquelas que lhe conferem relevância pela necessidade de caracterizar e encabeçar e polarizar toda uma nova geração de direitos fundamentais, como era mister fazer e ele não o fez. O direito à paz caiu em um esquecimento injusto por obra talvez da menção ligeira, superficial, um tanto vaga, perdida entre os direitos da terceira dimensão.

Todavia, pelo oportunismo histórico e por sua originalidade criativa e inovadora, o memorável artigo em prol de uma terceira geração de direitos do homem teve ressonância universal.

O abalizado publicista da UNESCO assinala naquele estudo "a emergência da paz como norma jurídica”; enunciado que por si só representava indubitavelmente um largo passo avante. Contudo não foi assim percebido ou conscientizado sequer pelo próprio autor.

Refere Vasak que essa emergência começou de ocorrer com a expedição de dois documentos históricos.

O primeiro documento foi a Declaração das Nações Unidas sobre a preparação das sociedades para viver em paz, constante da célebre Resolução 33/73, aprovada na 85ª sessão plenária da Assembléia Geral de 15 de dezembro de 1978.

Nessa Resolução a Assembléia Geral da ONU decreta que "toda nação e todo ser humano, independente de raça, convicções ou sexo, tem o direito imanente de viver em paz, ao mesmo passo que propugna o respeito a esse direito no interesse de toda a humanidade.”

O direito à paz é concebido ao pé da letra qual direito imanente à vida, sendo condição indispensável ao progresso de todas as nações, grandes e pequenas, em todas as esferas.

Referindo a necessidade de reconhecimento do direito à paz, a Resolução recorda dois instrumentos de consenso internacional que ela toma por base de apoio:

- A Declaração Universal dos Direitos do Homem, de 10 de dezembro de 1948 e

- O Pacto Internacional de Direitos Civis e Políticos, de 16 de dezembro de 1966.

O segundo documento é a proclamação da OPANAL (Organização para Proscrição das Armas Nucleares na América Latina) acerca da paz como direito do homem, conforme consta da não menos significativa Resolução 128(VI) de 27 de abril de 1979.

A Resolução aprovada pela OPANAL durante a Conferência Geral celebrada em Quito, no Equador, diz que compartilha o critério adotado na Resolução 33/73 da Assembléia Geral das Nações Unidas, de 18 de dezembro de 1978, de que todas as pessoas, os Estados e a humanidade têm o direito a viver em paz.

Do mesmo passo, pede que a Resolução por ela adotada seja levada ao conhecimento do Secretário Geral das Nações Unidas e do Diretor Geral da UNESCO “como expressão da vontade dos Estados que firmaram o Tratado de Tratelelco, de reconhecer, afirmar e garantir o direito à paz de seus países e de todas as pessoas que habitam em seus territórios.” 
Por derradeiro, é de assinalar a Declaração do Direito dos Povos à Paz, contida na Resolução 39, da ONU, de 12 de novembro de 1984.

A Declaração "proclama solenemente que os povos de nosso planeta têm o direito sagrado à paz.” E, empregando a mesma linguagem solene, acrescenta que "proteger o direito dos povos à paz e fomentar sua realização é obrigação fundamental de todo Estado."

\section{O RECONHECIMENTO DA PAZ COMO DIREITO NA DOUTRINA} E NA JURISPRUDÊNCIA

Não resultou fácil reconhecer, admitir e proclamar a natureza jurídica da paz, em sede teórica, como um conceito definido, autônomo, infenso a objeções porventura levantadas.

Disso teve ciência e consciência o insigne constitucionalista uruguaio Héctor Gross Espiéll quando inculcou, em reflexões acerca desse direito, algumas dificuldades com as quais se depara o jurista, vazadas deste teor:

“O direito à paz (...) é um direito mais complexo e que apresenta mais interrogações aos juristas. Por quê? Porque hoje em dia se tem buscado conceituar o direito à paz como um direito do qual podem ser titulares, segundo os diferentes casos ou situações, os Estados, os povos, os indivíduos e a humanidade. De tal modo que se tem podido dizer, como o fez Petiti, que como direito individual tem efeitos internos e internacionais e como direito coletivo também os tem ${ }^{1,}$.

Tocante à doutrina o contributo acerca do direito à paz tem sido deveras escasso, consideravelmente aquém da importância que se lhe deve conceder. ${ }^{2}$

Isto vem ocorrendo desde a publicação do artigo de Karel Vasak, o formulador da cognominada terceira geração de direitos fundamentais.

Com respeito à jurisprudência, o direito à paz, como bem acentua Nestor Pedro Sagüés $^{3}$, já figurou numa sentença da Sala Constitucional da Corte Suprema de Justiça da República de Costa Rica, proferida em 8 de setembro de 2004.

Naquela ocasião o Tribunal declarou inconstitucional o ato executivo de ingresso daquela república na coligação de Estados que, debaixo da liderança dos Estados Unidos, se propunham a intervir no Iraque, caso o governo desse País não cumprisse as resoluções das Nações Unidas pertinentes à proibição de armas estratégicas supostamente depositadas no território iraquiano pelo regime de Sadam Hussein.

\footnotetext{
${ }^{1}$ Héctor Gros Espiell, ”El derecho a la paz” in “Derechos Humanos y vida Internacional,” ob.cit., pp. 125/126

${ }^{2}$ Sobre a Paz, enquanto direito da terceira geração, ver: Karel Vasak, "Pour une troisième génération des droits de l'homme", aula inaugural do Curso do Instituto Internacional dos Direitos do Homem, em Estrasburgo, 1979; Pablo Eduardo Jiménez, "Los derechos humanos de la tercera generáción”, Buenos Aires, 1997, Editora Ediar; Ernesto Cantor Rey e Maria Carolina Ruiz Rodriguez, "Las generaciones de los derechos humanos”, $2^{\mathrm{a}}$ edição, Bogotá, Editora Página Maestra, 2003; Cecília Alaba Mayo de Ingaramo, "Herramientas y Mecanismos Constitucionales para la Protección Integral de los Derechos Humanos de la Tercera Generación”, Buenos Aires, 1997, Ed. Ediar; Paulo Bonavides, Curso de Direito Constitucional, 6 6 Edição, 1996 (janeiro), Malheiros, São Paulo.

${ }^{3}$ Néstor Pedro Sagüés, "Constitución y Sociedad: La Revisión de lãs Questiones Políticas no Justiciables (A propósito de la "Coalición contra Iraq", in "Revista Latino-Americana de Estudos Constitucionais”, $n^{\circ}$ 8, Fortaleza, 2007.
} 
O aresto é também de manifesta importância em matéria de jurisprudência constitucional, porquanto se afasta da célebre e clássica doutrina de Marshall, juiz da Corte Suprema dos Estados Unidos, o qual mantinha arredadas da esfera de sindicabilidade as questões políticas, salvo aquelas que porventura implicassem violação ou quebrantamento de direitos fundamentais, como bem assinalou Rui Barbosa.

Contudo, nosso interesse maior acerca da decisão da Corte de Costa Rica entende com um dos fundamentos do Acórdão, a saber, o direito à paz, reconhecido e aplicado como direito positivo. Admirável passo este que colocou a paz fora das esferas abstratas e programáticas e a introduziu num direito constitucional que tem vida e realidade e concretude!

Vejamos, a seguir, num extrato sumário e denso, da lavra de Néstor Sagüés, Presidente da Associação Argentina de Direito Constitucional, como se houve a Sala Constitucional costarriquenha ao aplicar aquele direito:

"Paralelamente, a Sala deteta a presença, nestas ações, do direito à paz, a que reconhece a condição de direito da terceira geração (...), do qual dá legitimidade a qualquer costarriquenho para defendê-lo. O Tribunal entende que se trata de um direito que diz respeito à coletividade em seu conjunto, como o atinente ao meio ambiente, ao patrimônio cultural, à defesa da integridade territorial do país e ao bom manejo do gasto público, e, por fim, segundo o art. $75, \S 2^{\circ}$ da lei de jurisdição constitucional (que em Costa Rica equivale a um código de processo constitucional) se reconhece legitimação processual a qualquer cidadão do país."4

\section{A VISUALIZAÇÃO DA PAZ ENQUANTO DIREITO DA QUINTA GERAÇÃO}

A paz, até ao Congresso Internacional Ibero-Americano de Direito Constitucional de 2006, celebrado em Curitiba, no Paraná, era nas considerações teóricas da literatura jurídica e nomeadamente da ciência constitucional contemporânea, segundo vimos, um direito quase desconhecido.

Karel Vasak o classificara entre os direitos da fraternidade, fazendo avultar, acima de todos, o direito ao desenvolvimento; o mais característico, portanto, em representar os direitos da terceira geração.

Tão característico e idôneo quanto a liberdade o fora em relação aos da primeira geração, a igualdade aos da segunda, a democracia aos da quarta e doravante a paz há de ser com respeito aos da quinta.

De último, a fim de acabar com a obscuridade a que ficara relegado, o direito à paz está subindo a um patamar superior, onde, cabeça de uma geração de direitos humanos fundamentais, sua visibilidade fica incomparavelmente maior.

Ontem, a Europa e a América do século XIX testemunharam a abertura da era constitucional, na idade moderna, em termos de universalismo.

Mas os dois continentes inauguravam em verdade durante as primeiras décadas

\footnotetext{
${ }^{4}$ Sentença da Sala Constitucional, da Corte Suprema de Costa Rica, apud Néstor Pedro Sagües, artigo citado.
} 
daquele século um constitucionalismo de vocação programática e idealista, inspirado no contrato social, doutrinário e abstrato, filosófico e racionalista, desde as nascentes.

Hoje, o ocidente, ao revés, assiste ao advento irresistível de outro constitucionalismo - o da normatividade - dinâmico e evolutivo e, ao mesmo passo, principiológico e fecundo na gestação de novos direitos fundamentais.

A concretização e observância desses direitos humaniza a comunhão social, tempera e ameniza as relações de poder; e faz o fardo da autoridade pesar menos sobre os foros da cidadania.

O novo Estado de Direito das cinco gerações de direitos fundamentais vem coroar, por conseguinte, aquele espírito de humanismo que, no perímetro da juridicidade, habita as regiões sociais e perpassa o Direito em todas as suas dimensões.

A dignidade jurídica da paz deriva do reconhecimento universal que se lhe deve enquanto pressuposto qualitativo da convivência humana, elemento de conservação da espécie, reino de segurança dos direitos.

Tal dignidade unicamente se logra, em termos constitucionais, mediante a elevação autônoma e paradigmática da paz a direito da quinta geração.

Eis o que intentaremos fazer ao longo das subseqüentes reflexões em busca de uma legitimação teórica imprescindível.

Vamos, por conseguinte, retirar o direito à paz da invisibilidade em que o colocou o edificador da categoria dos direitos da terceira geração.

Para tanto faz-se mister acender luzes, rasgar horizontes, pavimentar caminhos, enfim descerrar o véu que encobre esse direito na doutrina ou o faz ausente dos compêndios, das lições, do magistério de sua normatividade; lacuna, pois, que impende desde logo preencher.

Como fazê-lo, porém?

Colocando-o nas declarações de direitos, nas cláusulas da Constituição (qual se fez no art. $4^{\circ}$, VI da Lei Maior de 1988), na didática constitucional, até torná-lo, sem vacilação, positivo, e normativo e, uma vez elaborada a consciência de sua imprescindibilidade, estabelecê-lo por norma das normas dentre as que garantem a conservação do gênero humano sobre a face do planeta.

Epicentro, portanto, dos direitos da mais recente dimensão, a paz se levanta desse modo a uma culminância jurídica que a investe no mesmo grau de importância e ascendência que teve e tem o desenvolvimento enquanto direito da terceira geração.

Ambos legitimados sobreposse pela força e virtude e nobreza da respectiva titularidade: no desenvolvimento, o povo; na paz, a humanidade.

Com esse vasto círculo de abrangência dos direitos fundamentais ainda há espaço para erguer a quinta geração, que se nos afigura ser aquele onde cabe o direito à paz, objeto das presente reflexões.

Por isso lhe reservamos todo um capítulo desta obra, no qual se declinam as razões, os argumentos, as ponderações, a seguir desenvolvidas e expostas para legitimar tão merecida inserção. 


\section{A PRÉ-COMPREENSÃO DA PAZ: A ERA DA LEGITIMIDADE}

O Direito hoje está nas Constituições como ontem esteve nos Códigos. De último, sua legitimidade, após atravessar a crise das ideologias, assenta sobre princípios. Dentre estes um avulta por envolver todo o Direito: o princípio da constitucionalidade.

Antigamente, a legitimidade cabia toda na lei e nos códigos, porque não se desmembrava da legalidade.

O princípio legal, derivado da razão, que o amparava, regia todas as ramificações do poder.

Doravante, porém, com a legitimidade, sobreposta à lei, governa a Constituição os órgãos por onde a soberania se exerce.

Desde algumas décadas, a axiologia da justiça é o portal da legitimidade. Seu grau normativo é superior ao da legalidade.

Dantes, a lógica da razão, com a regra, a lei, o código; daqui por diante, o humanismo das idéias, com o valor, o princípio, a Constituição, a justiça.

Ao mesmo tempo, em termos de primazia, desponta nessa escala evolutiva a nova hermenêutica em substituição da hermenêutica clássica.

E o principio, donde tudo deriva, se faz de todo raiz da normatividade.

Desde o romper da idade principiológica, desserve a sociedade a figura do constitucionalista neutro.

Afogado, por inteiro, na teoria pura e na metodologia do formalismo, do dedutivismo, da subsunção, fica ele de costas voltadas para a circunjacência social, onde se insere a vida e a vida de seus semelhantes.

Em boa parte das repúblicas do hemisfério, a teoria constitucional faltará a um dever histórico de reflexão e discernimento se não refutar as diretrizes políticas e ideológicas da escola neoliberal. Ou seja, a fatalidade de seus rumos, a inanidade de seu magistério, a frouxidão de seus propósitos, e também a estranheza e impropriedade de sua receita amarga, dirigida a países privados de bases econômicas e sociais estáveis, onde ainda os direitos da primeira geração carecem, com freqüência, de garantias efetivas tocante a sua execução e positividade.

Nesse abismo da miséria política e social, abriu-se espaço à invasão das cognominadas ditaduras constitucionais; uma desgraça de que, a seguir, detidamente, nos ocuparemos.

\section{O FLAGELO DAS DITADURAS CONSTITUCIONAIS}

Com efeito, a Constituição não precisa de afirmar que a ditadura constitucional é criação inaceitável, é antinormatividade incrustada no ordenamento, é quinta-essência do arbítrio, é poder matriculado no absolutismo encoberto, a que se afizeram, por derradeiro, os genocidas das Cartas Magnas, os deflagradores de crises, os perpetuadores de golpes de Estado, os usufrutuários dos quadros e das quadras de exceção; enfim, toda aquela casta de liberticidas já identificados, os quais, no sumo, na essência, na substância, fazem a ditadura constitucional significar a inconstitucionalidade entronizada 
nas instituições. ${ }^{5}$

Repugna ao espírito da liberdade moderna, às garantias do Estado de Direito, aos fundamentos republicanos da organização política, aos cânones de legitimação dos poderes, um artefato tão vil, tão funesto à democracia, tão absurdo como a ditadura em questão.

E repugna justamente por ser a negação dos valores consagrados, a contrariedade dos princípios, a antinomia do direito, a contradição dos conceitos; algo, em suma, que, em sociedades onde os antigos súditos ainda caminham para a liberdade, agride a lógica, fere o sentimento, abala a fé, contradiz o bom senso, nega a verdade, menoscaba a justiça.

A inconstitucionalidade material se estampa assim visível e irrefragável em tão insólita ditadura, cuja obstinação raia na estupidez. Seus atos são lesivos, sua presença oposta à governabilidade democrática, sua existência incompatível com o espírito e as aspirações de nossa época.

Imperiosa, pois, a tarefa de pôr um dique à entrada desse vírus no organismo das repúblicas do Terceiro Mundo. Nelas regimes infratores da soberania popular têm, nas situações esdrúxulas de tamanha depravação do governo constitucional, a certidão falsa da existência de um Estado de direito que desde muito pereceu.

Urge, por conseguinte, expelir das instituições da democracia e da república, da ambiência livre, do pacto federativo, essa forma brutal de fraude e ofensa à Lei Suprema, flagelo nascido de Medidas Provisórias de um Poder que já não tem zelo nem consciência de seus deveres constitucionais.

O silêncio dos textos magnos, em países da periferia, certifica a ausência de provisões suscetíveis de tolher e erradicar aquele gênero de calamidade, que é a ditadura constitucional.

No entanto, tal silêncio condena já esse absolutismo de última geração, vestido de falsa legitimidade. E também o recusa e reprime, porque, como disse na tribuna portuguesa Latino Coelho, o grande publicista da liberdade, “o silêncio da Constituição é lei tão obrigatória como a sua palavra”. ${ }^{6}$

${ }^{5} \mathrm{O}$ testemunho da história não tem sido outro senão este: com a guerra os liberticidas abatem povos e sacrificam nações; com a paz os libertadores edificam repúblicas, restauram democracias, previnem genocídios. A paz é assim obra da divindade, a guerra arte do demônio. Toda democracia, em geral, é paz. Toda ditadura, ao revés, é guerra: aquela guerra civil latente entre opressores e oprimidos.

Se prosseguirmos o cotejo, fácil verificar que a guerra aparelha a ditadura, enquanto, a paz, a democracia, a qual, por sua vez, faz as nações prosperarem.

A paz cria valores, a guerra os destrói. Abençoada a paz que organiza e protege a liberdade do cidadão. Maldita a guerra que gera súditos e escravos, e esparge servidão e vassalagem entre os povos, propaga a morte e arruína civilizações.

Com a paz, o civismo constitucional forma a consciência da cidadania, e esta já não admite a Constituição como um código de retórica política, inchado de promessas, em que há mais ficção e demagogia do que concretude e normatividade; mais ausência do que presença dos fatores determinantes da governabilidade; mais desafeição e desfaçatez que fidelidade a valores e princípios.

A paz há de ser sempre jurídica, a guerra sempre criminosa. A paz pertence à Constituição, como um direito; a guerra, ao código penal, como um delito.

${ }^{6}$ Latino Coelho. O Preço da Monarquia. Lisboa, s/d, p. 24 
Demais disso, jamais ocorreria ao legislador constituinte que a Lei Maior tivesse a serventia de adjetivar e qualificar por constitucionais ditaduras dissimuladas, sistemas de exceção, deformações da democracia e do Estado de Direito, quais estas que ingressam no vocabulário político debaixo daquela locução. São da mesma família dos golpes de Estado institucionais, a saber, ocultos, oblíquos, subreptícios e ardilosos, distintos por igual dos golpes tradicionais, aqueles que derrubam governos, mas poupam instituições.

6. VICISSITUDES DA EVOLUÇÃO CONSTITUCIONAL DO BRASIL AO TEMPO DO IMPÉRIO

Somos com certeza povo e nação. Não somos cubata de servos nem multidão de súditos. Almejamos a paz, a compreensão, a fraternidade; por isso repulsamos, arrimados à consciência cidadã, o ultimato da soberba externa quando intenta destruir-nos a identidade, pois foi a identidade que constituiu o povo, criou a nação e estabeleceu as bases federativas e constitucionais do Estado brasileiro.

Depois de Tiradentes, martirizado no cadafalso da Inconfidência; depois dos heróis republicanos da Revolução Pernambucana de 1817, precursores do constitucionalismo luso-brasileiro e autores das célebres bases do primeiro projeto de Constituição em países de língua portuguesa; depois dos mártires constitucionais da Confederação do Equador, o Brasil deixou definitivamente de ser capitania hereditária dos donatários da Coroa portuguesa, deixou de ser casa grande e senzala dos latifúndios da cana de açúcar, deixou de ser território e colônia de opressores e oprimidos, para se converter, em razão de lenta metamorfose política, em império, república, nação e povo.

Naquelas jornadas da liberdade, o País escutou, com a autodeterminação, a voz de seu destino.

Aliás, é de ponderar que a trajetória da unidade desta nação foi obra sobretudo das circunstâncias sociais e políticas do século XIX, favorecida em parte pelas instituições centralizadoras do Império.

Teve a Constituição da monarquia, pedra angular do regime, seu grande momento de palavra-símbolo quando Hermeto Carneiro Leão, futuro marquês do Paraná, a invocou para conciliar o ânimo amotinado dos parlamentares e sacerdotes comprometidos com a execução do golpe de Estado, urdido em 1831 na Chácara da Floresta. Um desfecho bem sucedido dessa aventura política consumaria a outorga da Constituição de Pouso Alegre.

Graças, porém, à prudência e ao verbo de conciliação do estadista pernambucano, a Carta da realeza não veio abaixo naquele episódio.

Aliás, em ocasiões outras, até ao advento do Segundo Reinado com a Maioridade, o pulso de ferro da Regência, na conjuntura desagregadora, preveniu a queda dos poderes constituídos e a dissolução do Império.

7. EM PAÍSES PERIFÉRICOS NÃO VINGA ESTADO DE DIREITO SEM ESTADO SOCIAL: A NECESSIDADE PRECÍPUA DE PRESERVAR A SOBERANIA E FAZER DA PAZ UM DIREITO

A meu parecer, em termos de legitimidade e democracia, jamais há de prosperar, em países periféricos, Estado de Direito sem Estado Social. 
Mas os neoliberais da democracia negativa não têm a esse respeito o mesmo entendimento.

Forcejam por passar certidão de óbito à intangibilidade da garantia que protege os direitos sociais na Constituição.

Enquanto não logram esse desiderato, buscam mantê-los instáveis, debaixo da ameaça de revogação, ou, como se isto já fora possível, fazê-los retroceder vazios às esferas programáticas da Constituição, isto é, ao tempo que permaneceram relegados ao esquecimento e abandono na época clássica do constitucionalismo liberal.

Para tanto intentam agora nos despersuadir daquela verdade, vazada no aforismo da nova legitimidade, a qual consiste tocante às repúblicas periféricas em criar um Estado de Direito indissoluvelmente vinculado ao Estado Social, de preferência, ao Estado social da democracia participativa.

Com sustentarem, ao revés, o retrocesso, os juristas neoliberais disseminam a crença sobre a fatalidade da globalização, sofismada como um determinismo.

Baseados nisso lavram a sentença capital aos anseios dos povos da periferia nas batalhas constitucionais de sua emancipação.

A grande aspiração desses povos na contemporaneidade gravita ao redor da concretização dos direitos fundamentais das quatro dimensões ou gerações já conhecidas e consagradas, a saber, direitos individuais, direitos sociais, direitos dos povos, direitos universais. Compõem o credo da liberdade e o mandamento de consciência que percorre o campo da política e do constitucionalismo na América Latina. E do mesmo passo fazem a doutrina da soberania restaurar ali o dogma de sua inviolabilidade.

De tal sorte que as nações subdesenvolvidas do subcontinente não podem nem devem despojar-se da qualidade soberana de seu poder, nem tampouco deixar de professar um constitucionalismo de substrato principiológico; se o fizerem, o sopro espiritual de liberdade e resistência que perpassa o ânimo do povo, amparando a causa da nacionalidade, rapidamente decai e se extingue.

Soberania é princípio superlativo que consente a um povo concretizar a autodeterminação.

Os princípios sediados na Constituição, por serem princípios, regem e encabeçam toda a hierarquia normativa do regime.

Na sua junção com os direitos fundamentais, que também operam como princípios, a principiologia da Constituição forma a coluna vertebral do novo Estado de Direito.

A legitimidade deste deriva grandemente da confluência desses componentes normativos, a saber, princípios e direitos fundamentais.

Queremos, todavia, acrescentar um terceiro elemento constitutivo no coração da democracia: a paz, como direito fundamental da quinta geração.

Como se vê, vamos mais longe no sonho e na utopia, porque vislumbramos a esperança de que ela, a paz, concretize a associação da justiça com a democracia e a união do direito com a liberdade. 
8. O DIREITO À PAZ, UM DIREITO FUNDAMENTAL DE NOVA DIMENSÃO

Com efeito, em nosso tempo a alforria espiritual, moral e social dos povos, das civilizações e das culturas se abraça com a idéia de concórdia.

Essa idéia cativa a alma contemporânea, porque traz, consoante é mister, do ponto de vista juspolítico, uma ética que tem a probabilidade de governar o futuro, nortear o comportamento da classe dirigente, legitimar-lhe os atos e relações de poder.

Tal elemento de concórdia aliás vai deveras além da presente direção, propelido da necessidade de criar e promulgar aquele novo direito fundamental: o direito à paz enquanto direito de quinta geração.

Estuário de aspirações coletivas de muitos séculos, a paz é o corolário de todas as justificações em que a razão humana, sob o pálio da lei e da justiça, fundamenta o ato de reger a sociedade, de modo a punir o terrorista, julgar o criminoso de guerra, encarcerar o torturador, manter invioláveis as bases do pacto social, estabelecer e conservar por intangíveis as regras, princípios e cláusulas da comunhão política.

$\mathrm{O}$ direito à paz é o direito natural dos povos. Direito que esteve em estado de natureza no contratualismo social de Rousseau ou que ficou implícito como um dogma na paz perpétua de Kant.

Direito ora impetrado na qualidade de direito universal do ser humano.

A ordem interna dos ordenamentos jurídicos deste continente mostra que o ramo constitucional dos Poderes, que mais colide com a harmonia civil da sociedade é, sem dúvida, o Poder Executivo, cuja competência incha, cujos abusos se traduzem não raro em intervenções funestas à economia, ao desenvolvimento social, à política, e à legitimidade do sistema. Além de que, observa-se, o Poder Executivo tudo pode onde não prepondera a Constituição, onde a liberdade se abdica nos estratagemas do absolutismo, onde a centralização dos poderes desfigura o regime político, onde a fraca cidadania faz medrar a forte vocação dos caudilhos.

Coarctado o Judiciário, a república se desintegra, o fantasma da ditadura desponta, a Federação se desnatura e a sociedade, humilhada, começa de descrer na Justiça, que sempre foi, é e será a mais poderosa das garantias sociais, e a maior força auxiliar da liberdade.

Quando essa desintegração acontece, já não desempenha a Justiça o papel de escudo protetor do cidadão, de guardiã das franquias públicas, de baluarte dos direitos individuais e sociais. Tampouco exerce por sua magistratura suprema e pela jurisdição de seus Tribunais, a salvaguarda da Constituição e a tutela da ordem republicana.

Seguindo essa linha de pensamento, parece-nos indeclinável o dever constitucional de ir ao campo de batalha içar a bandeira da paz. A expressão campo de batalha parece, todavia, ambígua por inculcar um paradoxo ou uma contradição de sentido! Em rigor, busca-se a paz levantada ao máximo de juridicidade, em nome da conservação e do primado de valores impostos à ordem normativa pela dignidade da espécie humana.

De tal sorte que, coroados de feliz êxito, possamos trasladar essa paz das regiões da metafísica, da utopia, dos sonhos, onde demora neste mundo conflagrado, para a 
esfera da positividade jurídica, onde se deseja vê-la arraigada por norma do novo direito constitucional que ora se desenha: o direito constitucional do gênero humano.

Direito à paz, sim. Mas paz em sua dimensão perpétua, à sombra do modelo de Kant. Paz em seu caráter universal, em sua feição agregativa de solidariedade, em seu plano harmonizador de todas as etnias, de todas as culturas, de todos os sistemas, de todas as crenças que a fé e dignidade do homem propugna, reivindica, concretiza e legitima.

Quem conturbar essa paz, quem a violentar, quem a negar, cometerá à luz desse entendimento, crime contra a sociedade humana.

Aqui se lhe descobre então o sentido mais profundo, perpassado de valores domiciliados na alma da humanidade.

Valores, portanto, providos de inviolável força legitimadora, única capaz de construir a sociedade da justiça, que é fim e regra para o estabelecimento da ordem, da liberdade e do bem comum na convivência dos povos.

Execrado das presentes e das futuras gerações, o Estado que delinqüir ou fizer a paz soçobrar como direito, há por certo de responder ante o Tribunal das nações; primeiro no juízo coevo, a seguir, no juízo do porvir, perante a História.

Devemos assinalar doravante que a defesa da paz se tornou princípio constitucional, insculpido no art. $4^{\circ}$, inciso VI, da Constituição. Desde 1988, avulta entre os princípios que o legislador constituinte estatuiu para reger o país no âmbito de suas relações internacionais. E, como todo princípio na Constituição, tem ele a mesma força, a mesma virtude, a mesma expressão normativa dos direitos fundamentais. Só falta universalizá-lo, alçá-lo a cânone de todas as Constituições.

Vamos requerer, pois, o direito à paz como se requerem a igualdade, a moralidade administrativa, a ética na relação política, a democracia no exercício do poder.

No mundo globalizado da unipolaridade, das economias desnacionalizadas e das soberanias relativizadas e dos poderes constitucionais desrespeitados, ou ficamos com a força do direito ou com o direito da força. Não há mais alternativa. A primeira nos liberta, a segunda nos escraviza; uma é a liberdade, a outra, o cárcere; aquela é Rui Barbosa em Haia, esta é Bush em Washington e Guantánamo; ali se advogam a Constituição e a soberania, aqui se canonizam a força e o arbítrio, a maldade e a capitulação.

A ética social da contemporaneidade cultiva a pedagogia da paz. Impulsionada do mais alto sentimento de humanismo, ela manda abençoar os pacificadores.

Elevou-se, assim, a paz ao grau de direito fundamental da quinta geração ou dimensão (as gerações antecedentes compreendem direitos individuais, direitos sociais, direito ao desenvolvimento, direito à democracia). Fizemo-la, aliás, objeto de conferência em Curitiba, por ocasião do $9^{\circ}$ Congresso Ibero-Americano de Direito Constitucional, que teve a presença de 2.000 pessoas de 20 Estados da Federação e de outros países.

A paz logrou ali a dignidade teórica de um direito e de um princípio constitucional, constando da carta que o plenário daquela assembléia de juristas da América Latina e da Europa aprovou por aclamação. 
Subimos agora o derradeiro degrau na ascensão ao patamar onde, desde já, é possível proclamar também, em regiões teóricas, o direito à paz por direito da quinta geração, tirando-o da obscuridade a que dantes ficara confinado, enquanto direito esquecido da terceira dimensão.

Sede histórica e berço do novo mandamento normativo e da derradeira geração, ficou a capital do Paraná assinalada como tal a partir daquele evento, tanto quanto Foz de Iguaçu o ficara já em 1995 pelo direito à democracia, ali enunciado em Encontro de juristas e advogados de todo o continente.

Ambos os direitos nascidos, conforme se vê, de acontecimentos por extremo importantes e significativos para o meio jurídico deste País. Assim o foram entre nós, com certeza, as conferências nacionais da advocacia brasileira e os congressos de direito constitucional celebrados nos últimos vinte anos.

Em suma: dantes, a paz tida por direito fundamental nas regiões teóricas; doravante, porém, a paz erguida à categoria de direito positivo. Ontem, um conceito filosófico, hoje, um conceito jurídico. E tanto mais jurídico quanto maior a força principiológica de sua acolhida nas Constituições.

Há, em verdade, uma espécie de poder constituinte moral que, ao prescrever-lhe o reconhecimento normativo, cria um novo direito e busca, assim, garantir a sobrevivência do homem na idade dos artefatos nucleares e da explosão tecnológica.

A lição conclusiva destas reflexões se resume desse modo em fazer a paz axioma da democracia ${ }^{7}$, designadamente a democracia participativa, com seus instrumentos, com sua teoria, com seus valores de igualdade e justiça social, já inscritos por direito positivo pelos legisladores constituintes que promulgaram no Brasil, em 1988, a Carta republicana em vigor.

Fundamentando, enfim, a nova figura introduzida no rol dos direitos humanos, inspirada de dois filósofos da liberdade, dantes referidos, podemos asseverar que a guerra é um crime e a paz é um direito.

Sem a memória e a percepção dessa verdade gravadas na consciência dos povos e na razão dos governantes, nunca se concretizará a mais solene, a mais importante, a mais inderrogável cláusula do contrato social: o direito à paz como supremo direito da humanidade.

\footnotetext{
${ }^{7}$ Em 3 de setembro de 2006, a "Folha de S. Paulo” publicou o artigo “ Direito à Paz”, de nossa autoria, em que versamos o tema da paz elevada a direito da quinta geração.

Da França vieram dois depoimentos sobre esse trabalho: um do Professor François Julien-Laferrière, da Universidade Paris-Sul, onde é Diretor do Instituto de Estudos de Direito Público, outro de André-Jean Arnaud, Professor e Pesquisador Emérito da Universidade de Paris X - Nanterre

Julien-Laferrière assim se expressou: “ É muito interessante a reflexão sobre a relação entre a paz e a democracia e a conclusão de que a paz é um direito fundamental do homem e de toda a humanidade na sociedade contemporânea e que pode ser sancionada constitucionalmente". E assinalou que "sem a reflexão da doutrina o direito não avança.”

André-Jean Arnaud, também da Universidade de Paris, escreveu: “Trata-se de uma questão importantíssima: reconhecer a qualidade de conceito jurídico ao direito à paz; e reconhecer a importância do Direito num tempo de globalização.”
}

DIREITOS FUNDAMENTAIS E E JUSTIÇA N' 3 - ABR./JUN. 2008 